VOL. 48 (1993) [527-528]

\title{
Topographical effects in meteorology
}

\author{
Shaun R. Belward
}

The study of airflow over mountains dates from the early 1930s when glider pilots were the first people to experience the effects of lee waves directly. Until that time the only evidence for these waves was the lenticular (lens-shaped) clouds that are sometimes associated with them. Severe downslope winds are a different phenomenon from lee waves, but are often experienced over the same terrain. Unlike lee waves, downslope winds have been known for as long as settlement has occurred in mountainous areas since the effects of these winds are most severe in a layer of air close to the ground. We consider both of these atmospheric flows in this thesis.

To investigate airflow over mountains, we use two simple mathematical models. The first involves approximating the atmosphere by two layers of incompressible fluid, each of uniform density. Movement of fluid in each layer is irrotational and assumed uniform upstream of the mountain. The interface between the layers is unknown, and once determined, enables the calculation of various quantities within each layer of fluid.

The method of solution involves the use of boundary integrals (made possible since the flow is irrotational and incompressible). This gives three nonlinear integrodifferential equations which may be solved numerically after they have been discretised. The discretised equations are linear if a guess is made at the interfacial profile, and are solved using Newton's method.

Lee waves and downslope windstorms have been calculated using this model. Nonlinearity in lee wave flows is highlighted by comparing the nonlinear solutions against those obtained from a linear theory. In the downslope windstorm problem, the solutions obtained from the fully nonlinear theory are compared to those obtained from a shallow water theory.

The second mathematical model consists of a layer of constant density air flowing beneath a stationary, isothermal layer of air. The upper layer in this model approximates the upper atmosphere which is known to have nearly constant temperature. As with the previous model, the interface between the two fluids is to be computed. A

Received 6th July, 1993

Thesis submitted to the University of Queensland Febraury 1993. Degree approved June 1993. Supervisor Dr L.K. Forbes.

Copyright Clearance Centre, Inc. Serial-fee code: 0004-9729/93 \$A2.00+0.00. 
numerical technique similar to that employed for the first model is used in this second model.

The lee waves calculated with this model are different in profile to those computed previously. This highlights the effect of the compressible upper layer, and is consistent with results obtained by Forbes and Belward [1] who investigated periodic progressive waves at the interface between a fluid of constant density and an isothermal fluid, without concern for the mechanism of generation of the waves. Downslope windstorms were also calculated using this model, over the entire range of physically meaningful parameter values.

Finally in this thesis, we use our model with special parameter values to simulate single layer fluid flow in a channel. Our results contradict those obtained from an approximate nonlinear theory (the forced Korteweg - de Vries theory). The calculations we performed indicate that single layer critical flow and downstream waves may be calculated at the same parameter values, unlike in the forced Korteweg - de Vries theory which predicts that critical flow is a limiting form of downstream wave flow. This multiplicity of solutions is noted at parameter values which simulate atmospheric flows (that is, downslope windstorms and lee waves may occur at the same conditions), hence indicating a forecasting problem for meteorologists.

\section{REFerENCES}

[1] L.K. Forbes and S.R. Belward, 'Atmospheric interfacial waves', Phys. Fluids Ser. A 4 (1992), 2222-2229.

Department of Mathematics and Statistics

James Cook University of North Queensland

Townsville, Qld 4811

Australia 